\title{
CÓDIGO PENAL BRASILEIRO COMO DESCRIÇÃO DE PRÁTICA CULTURAL: UMA ANÁLISE COMPORTAMENTAL DE CONTINGÊNCIAS E METACONTINGÊNCIAS
}

\author{
BRAZILIAN PENAL CODE AS DESCRIPTION OF A CULTURAL PRACTICE: A BEHAVIORAL ANALYSIS OF \\ CONTINGENCIES AND METACONTINGENCIES
}

\author{
VITOR MIRANDA ARAUJO \\ CAMILA MUCHON de MELO \\ VERÔNICA BENDER HAYDU
}

UNIVERSIDADE ESTADUAL DE LONDRINA, BRASIL

\begin{abstract}
RESUMO
O Código Penal Brasileiro é a lei que determina quais os critérios para considerar um ato de um cidadão como criminoso e os critérios para responsabiliza-los por esses atos. Também determina os parâmetros do julgamento e da pena para cada crime. Neste estudo, a lei penal é analisada sob a perspectiva da Análise do Comportamento, usando como método a identificação de descrições de contingências de três termos e metacontingências nos artigos do código. O código aqui foi considerado como a descrição de contingências comportamentais e de práticas culturais. Foram identificadas descrições completas e incompletas de contingências individuais e de contingências entrelaçadas de comportamentos de cidadãos e agentes legais. Discute-se a efetividade do código em controlar o comportamento das pessoas, analisando a distribuição dos artigos e o tipo de controle que é exercido. Por fim, conclui-se que para que o Código Penal possa ser efetivo numa função de evitar comportamentos violentos e promover a segurança da população, ele não pode ser visto isoladamente. É fundamental entendê-lo como um elo de entrelaçamentos complexos que envolvem outras leis e outras práticas de agências não diretamente ligadas à formulação do Código, para que ele possa ter uma função preventiva.
\end{abstract}

Palavras chave: Código Penal, Lei, Prática cultural, Metacontingência.

\section{ABSTRACT}

The Brazilian Penal Code is the law that determines criteria for considering acts practiced by citizens as crimes as well as criteria to make them responsible for these acts. It also establishes judgement and sentences parameters for each crime. In this study, penal law is analyzed under the Behavior Analysis perspective, using, as method, the identification of contingencies descriptions of three terms and metacontingencies in the articles of the code. The code here was considered as a description of behavioral contingencies and cultural practices. Complete and incomplete descriptions were found of individual contingencies and interlocked contingencies of citizens' behaviors and legal agents. The efficacy of the code in controlling people's behavior is discussed by analyzing the distribution of the articles and the type of control exercised. Finally, it was concluded that, for the Penal Code to be effective in preventing violent behavior and promoting safety for the population, it cannot be analyzed in isolation. For it to have a preventive function, it is essential to understand it as part of a complex interlocking that involves other laws and other practices of agencies not directly connected to the formulation of the Code.

Keywords: Penal Code, Law, Cultural Practice, Metacontingency.

Este trabalho foi financiado parcialmente pela bolsa de mestrado do Programa de Demanda Social da CAPES concedida ao primeiro autor. Verônica Bender Haydu é bolsista produtividade em pesquisa da Fundação Araucária. Endereço eletrônico para contato: araujo.vitor86gmail.com 
O Código Penal Brasileiro, implementado pelo Decreto-Lei $n^{\circ}$ 2.848, de 7 de dezembro de (Brasil, 2012), regulamenta as ações relacionadas à responsabilização de atos ilícitos criminosos no Brasil. Assim, o Código Penal descreve quais as condições em que determinadas ações devem ser punidas e os comportamentos esperados dos agentes judiciais para promover a responsabilização dos indivíduos criminosos. Em termos comportamentais: o Código Penal descreve contingências de três termos (Skinner, 1953) que devem estar em vigor no Brasil com relação a comportamentos que são prejudiciais à sociedade. Portanto, há no Código Penal descrição de (a) condições ambientais diante das quais (b) respostas específicas recebem (c) consequências aversivas previstas para diminuir a frequência dos comportamentos especificados. Além disso, prescreve comportamentos esperados dos agentes da justiça.

O código pode ser considerado também como a descrição e produto de metacontingências (Glenn \& Malott, 2004; Malott \& Glenn, 2006) que supostamente teriam como produto agregado o efetivo cumprimento da lei, que no sistema político e social, adequado para funcionar como o sistema receptor (Glenn \& Malott, 2004), tem como consequência cultural a segurança das pessoas ou pelo menos a sensação de segurança, que mantém esse entrelaçamento. Para as autoras citadas, um produto agregado é o resultado mais direto de contingências comportamentais entrelaçadas que só pode ser produzido pela interação dessas contingências e não é a soma do resultado imediato de cada comportamento que faz parte do entrelaçamento. Por sua vez, o sistema receptor é o ambiente adequado para que esse produto agregado seja útil, gerando uma consequência cultural que seleciona o entrelaçamento e o produto agregado.

O texto do código pode ser analisado tanto como um produto do entrelaçamento de contingências principalmente de comportamentos de legisladores quanto como descrição e componente de outro entrelaçamento que teria como produto agregado a segurança. $\mathrm{O}$ sistema receptor, para que ambas metacontingências produzam a consequência cultural prevista em longo prazo, é o estado democrático de direito.

Ao se propor analisar a Constituição Federal, Todorov (1987, p. 9) afirma que: "Uma lei que se preze sempre prescreve alguma consequência para algum tipo de comportamento". E inclui o Código Penal entre o tipo de lei que prescreve consequências punitivas na tentativa de controlar comportamentos que se queira diminuir de frequência em uma cultura. Assim, "O Código Penal autoriza certos agentes a aplicar punição, especificando os parâmetros do processo" (Todorov, 1987, p. 9). Assim, as leis são a codificação dos procedimentos de controle da agência governamental (Todorov, 2005) e o Código Penal, enquanto lei, pode ser classificado como estímulo discriminativo verbal (Skinner, 1957) do tipo regra (Skinner, 1957, Albuquerque, Paracampo, Matsuo, \& Mescouto, 2013) e, como tal, se presta à análise comportamental. A legislação é também considerada a descrição de uma prática cultural, ou seja, a descrição de comportamentos controlados por consequências culturais que são reproduzidos dentre os membros da cultura (Moreira, Machado, \& Todorov, 2013) e que podem ser transmitidos para outra geração. Como descrição de comportamento, então, o Código Penal pode e deve ser analisado sob uma perspectiva da Análise do Comportamento, na expectativa de que se possa lidar melhor com as práticas descritas e se necessário buscar mudanças com o intuito de melhorar seu controle sobre o comportamento e sobre as práticas culturais. Bem como, melhorar a efetividade em alcançar os seus objetivos.

A Análise do Comportamento não se restringe ao estudo de comportamentos individuais. Análises de processos culturais a partir dos métodos e conceitos de uma ciência do comportamento (Skinner, 1953) e de uma filosofia behaviorista radical (Skinner, 1974) fazem parte do escopo dessa ciência (Todorov, 2009). A possibilidade dessas análises está embasada na constatação de que práticas culturais são compostas por comportamentos, que, apesar de possivelmente dependerem do ambiente social para acontecer, não tem natureza ontológica diferente de comportamentos individuais isolados, e são regidos pelas mesmas leis conforme apontou Castro (2013). Olhar para o Código Penal a partir de uma perspectiva analíticocomportamental, como a apresentada por Moreira, Machado e Todorov (2013) é olhar para um aspecto da cultura que permanece entre gerações e buscar uma análise que possibilite a identificação das variáveis que proporcionaram o surgimento e a manutenção dessa prática. É, também, explicar as possíveis modificações ocorridas e possibilitar a previsão de um possível colapso e, assim, a tentativa de impedi-lo.

Sob essa perspectiva, outras análises sobre legislação já foram realizadas (e.g., Cabral, 2014; Carvalho, 2013; Lourencetti, 2015; Machado, 2007; Martins, 2009; Todorov, 1987, 2005, 2009; Todorov, Moreira, Prudêncio, \& Pereira, 2004). Esses trabalhos trouxeram contribuições quanto a sugestões prévias de critérios a serem usados na confecção da legislação, quanto à análise de problemas estruturais na lei investigada que podem influenciar na sua execução ou como planejamento cultural para facilitar o cumprimento da lei em questão.

A análise da Constituição como metacontingência feita por Todorov (1987) é inicial e apenas descreve alguns processos e entrelaçamentos de contingências comportamentais que foram importantes no processo de redemocratização no Brasil, conforme aponta o próprio autor. Apesar de o autor nesse estudo utilizar ainda a primeira formulação do conceito de metacontingência e, portanto, não detalhar aspectos importantes desse processo sociocultural, ele sugeriu que esse conceito é apropriado para análise de práticas culturais.

Assim, o presente estudo visa analisar o Código Penal Brasileiro a partir de um método comportamental para análise de textos legais descrita por Todorov et al. (2004) e utilizada por Martins (2009), Carvalho (2013) e Cabral (2014). Além disso, visa fazer considerações sobre o uso de contingências aversivas (predominantes 
no Código Penal) e do uso de controle por regras de forma predominante por uma cultura, e analisar condições de responsabilização descritas pelo Código.

A análise comportamental do Código Penal destaca as descrições classificadas como regras e como práticas culturais. Portanto, será apresentado a seguir o modelo de seleção por consequências, com destaque para o nível cultural com o estudo da evolução de práticas culturais e, ainda, relações verbais ou o comportamento verbal e alguns de seus efeitos. A abordagem da terminologia utilizada como regras presentes em leis é necessária para o desenvolvimento de pesquisas e intervenções analítico- comportamentais.

\section{Seleção por Consequências}

O modelo de seleção por consequências (Skinner, 1981) se contrapõe a explicações mentalistas e explicações mecanicistas do comportamento propondo explicações históricas que seriam uma alternativa cientificamente válida para o estudo do comportamento (Baum, 2005, Skinner, 1981). Tal modelo explica o comportamento pelo seu valor de sobrevivência e reprodução, porém, como Skinner deixa claro, o organismo não se comporta para ser mais apto a sobreviver e reproduzir. Determinados comportamentos que tornaram o organismo mais apto são selecionados por essas consequências.

Essa seleção acontece em três níveis: filogenético, ontogenético e cultural (Skinner, 1981). No nível filogenético ocorre a seleção natural das espécies; algumas características comportamentais são selecionadas nesse nível e servem de "matéria prima" para o segundo nível de seleção. No segundo nível, comportamentos operantes são selecionados quando produzem consequências reforçadoras e comportamentos respondentes podem ser condicionados na presença de novos estímulos. Por fim, no terceiro nível comportamentos, são selecionados quando produzem consequências importantes para o grupo, ou seja, que colaboram para a resolução dos problemas do grupo em geral e, por isso, são reforçados por eles por seus membros (Skinner, 1971/1973).

\section{Práticas culturais}

Assim como comportamentos selecionados no nível filogenético são base para a ontogenia, os comportamentos selecionados no segundo nível são a "matéria prima" para a seleção no nível cultural. A seleção só pode ocorrer a partir da variação e é a variação de comportamentos individuais que pode ser selecionada pela cultura quando esses comportamentos têm valor para o grupo. Tais comportamentos são reproduzidos entre os indivíduos de um grupo por terem sido reforçados por seus membros, tornando-se uma prática cultural que é mantida por tais reforçadores e transmitida para as gerações seguintes, conforme descreveram Dittrich, Melo, Moreira e Martone (2013). Esses autores chamam atenção para a importância de distinguir o segundo do terceiro nível (a transmissão entre gerações é um dos critérios para essa distinção) e de entender o porquê das práticas serem transmitidas.
É fundamental compreender esse ponto para que a distinção entre os Níveis 2 e 3 (ontogenético e cultural) fique clara. Práticas culturais são transmitidas entre gerações porque aqueles que as transmitem são reforçados por fazê-lo. O reforço pode ser direto, por meio do comportamento daquele(s) para o(s) qual(is) a prática é transmitida ou indireto, por meio de agências governamentais, educacionais, religiosas, etc. ou de outras formas de reforço social dos comportamentos envolvidos na transmissão da prática. (Dittrich et al., 2013. p.47)

Os grupos que reforçam e mantêm comportamentos de seus membros como práticas culturais frequentemente não têm, em sua totalidade, uma organização adequada e não adotam procedimentos sistematizados, porém parcelas desses grupos têm poder de manipular uma boa parte das variáveis de controle do comportamento. São esses membros organizados do grupo que Skinner (1953) denominou agências de controle. $\mathrm{O}$ Governo é uma das agências de controle citadas por Skinner, que tem poder sobre muitas variáveis de controle do comportamento. Essa agência utiliza, de forma constante, o controle aversivo e seu poder deriva e é regulamentado por meio de leis. Segundo Todorov (2005), as leis são a codificação do controle do Estado.

Quando se fala em seleção por consequências a tendência é entender que todas as características que são mantidas, seja em qualquer um dos três níveis, são necessariamente boas. Isso pode ser considerado um equívoco em pelo menos dois sentidos. Primeiro, assumir que se uma prática foi selecionada ela então deve ser boa é um erro porque uma prática é selecionada por um ambiente cultural específico e esse ambiente pode mudar sem que a prática mude. Assim uma prática boa pode deixar de o ser quando o ambiente cultural mudar ou ela pode ser boa apenas para alguns dos membros desse ambiente. Além disso, pode-se considerar problemática a atribuição de valor positivo a uma prática a priori, pois ela pode ser prejudicial, tendo sido selecionada em conjunto com outra prática produtiva. Essa explicação é importante para que nenhuma prática seja considerada como boa sem uma análise cuidadosa das contingências. Assim, considerar o seguimento do Código Penal como uma prática cultural que foi selecionada pela cultura brasileira não dá a ele o status de uma boa prática per se.

\section{Comportamento Verbal}

O Código Penal é uma lei e isso significa, segundo Skinner (1953), que ele aponta um comportamento e diz qual a consequência para esse comportamento, ou seja, "é um enunciado de uma contingência de reforço” (p. 370). Essa característica de especificação de comportamento e suas consequências é o que Skinner (1957) identifica como sendo "regras". As leis são regras que são registradas em textos, assim, são produtos de comportamento verbal e também estímulos discriminativos para outros comportamentos, verbais ou não.

O comportamento verbal não é diferenciado de outros comportamentos por qualquer característica ontológica, mas sim pelo modo que o comportamento 
opera no mundo (Barros, 2003). Ele não pode ser distinguido por sua topografia, nem pode ser representativo de um significado. Como qualquer comportamento, o verbal é adquirido e mantido por seus efeitos no ambiente, ou seja, por sua função (Barros, 2003). O comportamento não verbal tem efeito sobre o mundo por mecanismos geométricos e mecânicos, porém o comportamento verbal não tem poder sobre o mundo físico de forma direta. "Seu primeiro efeito é sobre outro Homem" (Skinner, 1957, p. 1). Entender a operação do comportamento verbal exige minimamente a análise do comportamento de dois indivíduos, um falante e um ouvinte.

A emissão de regras tem a característica de beneficiar prioritariamente o falante no sentido de promover comportamentos do ouvinte, que produzam consequências reforçadoras para o primeiro (Skinner, 1957). Então, uma regra deve produzir mudanças no comportamento do ouvinte e ela o faz de duas formas diferentes: ou ela produz modificações imediatas no comportamento do ouvinte (agindo como estímulo discriminativo), fazendo com que ele se comporte conforme a especificação da regra ou ela altera a forma com que o ouvinte reage a determinados estímulos (operação estabelecedora) (Paracampo \& Albuquerque, 2005). Dessas duas formas, uma regra tem a função de "ponte" entre os comportamentos e as consequências que não estão disponíveis imediatamente (Páramo, 2013).

Ainda tratando de como o comportamento verbal opera no mundo, é importante observar, não obstante, que a modificação produzida pelo ouvinte pode não ter, e geralmente não tem, relação direta com a forma do comportamento do falante. Para dar um exemplo voltando para o objeto deste estudo, o legislador que cria uma regra proibindo a venda de drogas não tem como consequência imediata de seu comportamento a redução da venda desse produto, mas provavelmente acontecerá outra modificação no ambiente, por exemplo, a aprovação de colegas e da população em geral. Tais consequências fazem parte do entrelaçamento de contingências comportamentais da metacontingência que tem o Código Penal como produto. É essa consequência social que provavelmente mantém o comportamento de fazer leis e não a consequência prevista no texto legal.

O Código Penal, então, enquanto lei é produto de uma prática cultural verbal. Portanto, é selecionado por consequências estabelecidas no grupo, que no caso específico, são controladas pela agência governamental. Isso é de suma importância para determinar a fonte do poder que a lei possa ter. O poder de controle das leis é fruto do controle exercido pela agência governamental, que determina as práticas de produção das leis e também garante que suas prescrições sejam cumpridas.

Esclarecidas as questões sobre seleção por consequências, práticas culturais e comportamento verbal que foram anunciadas como necessárias, retoma-se os objetivos deste trabalho, que são: analisar o Código Penal a partir de um método específico, descrito a seguir para, a partir dessa análise, debater sobre a predominância da prescrição de controle aversivo e do uso prioritário de regras por uma cultura e, também, fazer uma análise das condições de responsabilização propostas no código.

\section{Material \\ MÉTODO \\ O objeto deste estudo é o Código Penal} Brasileiro, Lei $n^{\circ} 2.848$, de 7 de dezembro de 1940, de acordo com as alterações mais recentes dadas pela Lei $\mathrm{n}^{\circ}$ 12.720 de 2012, considerado como a descrição de um conjunto de contingências comportamentais entrelaçadas e uma metacontingência (Glenn \& Malott, 2004; Malott \& Glenn, 2006). O Código Penal é dividido em 11 títulos subdivididos em capítulos, com 359 artigos, mais as disposições finais com dois artigos.

\section{Instrumento de Análise}

O instrumento de análise utilizado neste estudo foi o mesmo utilizado por Todorov et al. (2004), por Martins (2009), Carvalho (2013) e Cabral (2014). Ou seja, a descrição da contingência operante de três termos, "com o objetivo de identificar termos da contingência nos artigos e agrupar os antecedentes, comportamentos e consequências de uma mesma contingência" (Todorov et al. 2004, p.45). Os artigos do Código Penal Brasileiro foram classificados em: (a) antecedentes (b) respostas e (c) consequências. Como critério de classificação, respectivamente os artigos devem descrever (a) os contextos e condições em que as respostas devem ocorrer; (b) as respostas esperadas, ou condenadas, de um indivíduo; e (c) as consequências diretas de cada resposta nessa contingência.

Os artigos também foram analisados como descrição de contingências comportamentais entrelaçadas que geram ou deveriam gerar um produto agregado num contexto especificado.

\section{Procedimento}

Os artigos do Código Penal Brasileiro foram classificados de forma a se poder identificar os termos da contingência. Identificou-se, assim, se cada artigo representava um antecedente, uma resposta ou uma consequência. Posteriormente, foi feito o agrupamento de artigos que descrevessem os termos de uma mesma contingência. Esse agrupamento se tornou importante principalmente porque os artigos que descrevem termos de uma contingência não necessariamente foram encontrados na mesma parte do texto. Alguns artigos eram somente explicativos de outros artigos ou apenas classificavam conceitos jurídicos ou tipos de medidas, por isso não entraram na classificação. Houve ainda a separação de descrições completas e incompletas de contingências. Essa separação levou em conta a presença dos três termos da contingência no Código Penal.

\section{RESULTADOS E DISCUSSÃO}

A classificação das descrições contidas no Código Penal possibilitou a identificação de comportamentos de membros de uma determinada cultura (brasileira) e membros da agência de controle 
governamental e, também, facilitou a visualização de entrelaçamentos das contingências comportamentais dessas pessoas. Os pesquisadores consideraram nessa análise que a consequência cultural que mantém esses entrelaçamentos é o controle do comportamento dos membros dessa cultura no sentido de diminuir comportamentos prejudiciais aos outros membros e para as agências governamentais, em termos gerais, a segurança dos membros e das agências. Identificou-se então que o Código Penal é produto de uma metacontingência e que está inserido em outras metacontingências mais complexas.

\section{Descrições de Contingências Completas e Incompletas}

Foram encontradas no Código Penal descrições de contingências completas e incompletas. Foram consideradas descrições completas aquelas que especificam quais as consequências previstas para uma resposta. Em geral, os artigos contidos na "Parte Especial" do código são bons exemplos de contingências completas e, nesses casos, o mesmo artigo descreve várias contingências, com especificações de consequências diferentes previstas para uma mesma resposta em condições antecedentes diferentes. Por exemplo:

Art. 121. Matar alguém:

Pena - reclusão, de seis a vinte anos.

$\S 1^{\circ}$ Se o agente comete o crime impelido por motivo de relevante valor social ou moral, ou sob o domínio de violenta emoção, logo em seguida a injusta provocação da vítima, ou juiz pode reduzir a pena de um sexto a um terço.

$\S 2^{\circ} \mathrm{Se}$ o homicídio é cometido:

I - mediante paga ou promessa de recompensa, ou por outro motivo torpe;

II - por motivo fútil;

III - com emprego de veneno, fogo, explosivo, asfixia, tortura ou outro meio insidioso ou cruel, ou de que possa resultar perigo comum;

IV - à traição, de emboscada, ou mediante dissimulação ou outro recurso que dificulte ou torne impossível a defesa do ofendido;

V - para assegurar a execução, a ocultação, a impunidade ou vantagem de outro crime:

Pena - reclusão, de doze a trinta anos.

$\S 3^{\circ} \mathrm{Se}$ o homicídio é culposo: (Vide Lei $\mathrm{n}^{\circ} 4.611$, de 1965)

Pena - detenção, de um a três anos.

$\S 4^{\circ}$ No homicídio culposo, a pena é aumentada de $1 / 3$ (um terço), se o crime resulta de inobservância de regra técnica de profissão, arte ou ofício, ou se o agente deixa de prestar imediato socorro à vítima, não procura diminuir as consequências do seu ato, ou foge para evitar prisão em flagrante. Sendo doloso o homicídio, a pena é aumentada de $1 / 3$ (um terço) se o crime é praticado contra pessoa menor de 14 (quatorze) ou maior de 60 (sessenta) anos. (Redação dada pela Lei ${ }^{\circ} 10.741$, de 2003)

$\S 5^{\circ}$ - Na hipótese de homicídio culposo, o juiz poderá deixar de aplicar a pena, se as consequências da infração atingirem o próprio agente de forma tão grave que a sanção penal se torne desnecessária. (Incluído pela Lei $n^{\circ}$ 6.416, de 24.5.1977)
$\S 6^{\circ}$ - A pena é aumentada de $1 / 3$ (um terço) até a metade se o crime for praticado por milícia privada, sob o pretexto de prestação de serviço de segurança, ou por grupo de extermínio. (Incluído pela Lei $\mathrm{n}^{\circ}$ 12.720, de 2012)

Pode-se notar que esse artigo descreve além da resposta condenável "matar alguém", a consequência que tal resposta deve ter, a consequência punitiva para essa ação, "prisão", e condições nas quais o ato é menos ou mais condenável, com as consequências para o comportamento se ocorrerem nessas condições. Por exemplo, a possibilidade de aplacar a pena se o agente estiver "impelido por motivo de relevante valor social ou moral, ou sob o domínio de violenta emoção, logo em seguida a injusta provocação da vítima". Destaca-se a importância da descrição das consequências. O controle por regra tem várias nuances e há indícios de que a descrição completa das contingências é uma variável facilitadora do cumprimento de uma regra (Abreu \& Hübner, 2011; Albuquerque \& Paracampo, 2010).

$\mathrm{Na}$ maioria dos artigos não são descritas as condições antecedentes para ação, mas como se poderá observar, o Código Penal descreve alguns antecedentes gerais, permitindo que sejam consideradas descrições completas aquelas que minimamente descreverem a ação e a consequência. As descrições incompletas são aquelas que descrevem apenas a condição e a resposta sem descrever as consequências previstas para tal comportamento ou para a não emissão do mesmo. Esse tipo de contingência é, em geral, descrição de comportamentos esperados por agentes do governo (juízes, delegados, força policial ou penitenciaria). Um exemplo é o art. 59, que descreve como o juiz deve agir para fixar uma pena, mas não diz qual a consequência esperada para tal ação ou qual a consequência de não se comportar segundo essa determinação.

Art. 59 - O juiz, atendendo à culpabilidade, aos antecedentes, à conduta social, à personalidade do agente, aos motivos, às circunstâncias e consequências do crime, bem como ao comportamento da vítima, estabelecerá, conforme seja necessário e suficiente para reprovação e prevenção do crime: (Redação dada pela Lei $n^{\circ} 7.209$, de 11.7.1984)

I - as penas aplicáveis dentre as cominadas; (Redação dada pela Lei $n^{\circ} 7.209$, de 11.7.1984)

II - a quantidade de pena aplicável, dentro dos limites previstos; (Redação dada pela Lei $\mathrm{n}^{\circ} 7.209$, de 11.7.1984)

III - o regime inicial de cumprimento da pena privativa de liberdade;(Redação dada pela Lei $\mathrm{n}^{\circ}$ 7.209, de 11.7.1984)

IV - a substituição da pena privativa da liberdade aplicada, por outra espécie de pena, se cabível. (Redação dada pela Lei $n^{\circ} 7.209$, de 11.7.1984)

Possivelmente as consequências que não são descritas para esses comportamentos são descritas em legislação especial, que regulamenta as ações desses agentes do governo. Apesar dessas legislações estarem fora do âmbito da análise feita no presente estudo, essa informação se torna relevante se o Código Penal for 
considerado como parte integrante de uma metacontingência maior que poderia ser denominada legislação brasileira. A legislação como um todo é fruto de um entrelaçamento complexo de contingências comportamentais que pretende produzir um ordenamento social baseado em leis, essas leis, além de não serem independentes, podem ser complementares. Assim, a descrição de uma contingência não precisaria ser fruto apenas dos comportamentos dos legisladores que produziram o Código Penal, podendo ser complementadas pelos comportamentos daqueles que desenvolveram a regulamentação das funções dos magistrados, por exemplo.

De toda forma, seria recomendável a descrição completa da contingência com o objetivo de aumentar a efetividade do controle do Código Penal sobre o comportamento desses agentes. Além do mais, a descrição incompleta pode diminuir a possibilidade de contra controle. Enquanto agência de controle, o Governo tem grande poder sobre variáveis que determinam o comportamento dos cidadãos, apesar de fazer de tudo para esconder que esse controle pode ser e geralmente é aversivo (Skinner, 1971/1973; Todorov, 2005). Segundo Skinner (1971/1973), é importante que o restante do grupo, com menos poder, tenha acesso ao que pode controlar o comportamento dos participantes das agências, diminuindo, assim, o poder dela e impedindo excessos.

É facilmente observado também, que o tipo de controle descrito pelo Código Penal é o controle aversivo. Percebe-se que todas as consequências descritas nos artigos têm caráter punitivo e são apresentadas com o objetivo de diminuir a frequência de certas respostas. Tais consequências são prescritas sempre para comportamentos condenáveis, porém o código negligencia as consequências dos comportamentos que se espera que aconteçam. Esse tipo de controle tem efetividade controversa (Catania, 1999; Sidman, 1989/2003) e também se discute eticamente o uso prioritário desse tipo de controle (Catania, 1999; Sidman, 1989/2001; Skinner, 1971). Apesar de o controle aversivo existir na natureza, programar esse tipo de consequência não é recomendado por esses autores.

\section{Descrição de Antecedentes Gerais}

Um mesmo artigo do Código Penal pode descrever antecedentes de mais de uma contingência. Assim como algumas contingências necessitam de um conjunto de condições e essas se encontram em dois ou mais artigos. Um exemplo é o caput do art. 13 que coloca condição para aplicação da consequência prevista para vários comportamentos:

Art. 13 - O resultado, de que depende a existência do crime, somente é imputável a quem lhe deu causa. Considera-se causa a ação ou omissão sem a qual o resultado não teria ocorrido. (Redação dada pela Lei $\mathrm{n}^{\circ}$ 7.209, de 11.7.1984)

Ao dispor, de forma geral, que só é considerável crime a ação da qual decorrer resultado passível de punição segundo a lei, o artigo coloca todas as ações condenáveis descritas na Parte Especial do Código Penal, em condição de não ser passível de punição se por algum motivo seu efeito não ocorrer. Além disso, esse mesmo artigo coloca uma condição para várias ações dos agentes governamentais ao estipular que somente quem deu causa à ação pode ser responsabilizado pelo mesmo. Porém, o Artigo 13 não descreve a única condição necessária para que uma pena seja aplicada. Muitas outras são descritas no Código Penal sem as quais a ação de julgar um sujeito como culpado e puni-lo não é possível, como o Artigo 27 que coloca a condição de que seja necessário que o sujeito causador da ação tenha pelo menos 18 anos de idade na data do crime:

Art. 27 - Os menores de 18 (dezoito) anos são penalmente inimputáveis, ficando sujeitos às normas estabelecidas na legislação especial. (Redação dada pela Lei $n^{\circ}$ 7.209, de 11.7.1984).

\section{Responsabilização}

O Título III da Sessão Geral do Código Penal é de especial importância para a discussão sobre a responsabilização. Ele trata da Imputabilidade e apresenta condições que podem ser alocadas tanto nas contingências comportamentais dos agentes da lei quanto dos cidadãos que estão sujeitos a ela. Skinner (1953) chama atenção para o critério usado para que a agência governamental considere um comportamento legal ou ilegal. Segundo o autor, comportamentos que podem ser prejudiciais para a agência governamental (Skinner, 1953) são considerados ilegais. Pode-se identificar relação entre essa afirmação do autor e os critérios utilizados para considerar um sujeito inimputável. A lei prescreve que o indivíduo que comete um ato criminoso não seja punido se ele não for considerado responsável pelos seus atos. Por "não responsáveis" se quer dizer que não teriam controle sobre sua ação. Assim, não responsabilizar penalmente um esquizofrênico, por exemplo, não teria consequências negativas para o prestigio da agência. Essa postura pode ser questionável se for considerado que a consequência cultural que deveria estar controlando a manutenção dessa prática seria a segurança da população e não a simples penalização dos responsáveis. Novamente, os outros códigos que podem prescrever ações que resolvam tais problemas, como o ECA (Estatuto da Criança e do Adolescente), que descreve como os menores que cometem infrações devem ser responsabilizados, não estão sendo considerados. Precisa-se considerar que o Código Penal é parte de uma metacontingência maior.

Há algumas situações descritas ao longo do Código Penal que são circunstâncias para o abrandamento ou o endurecimento da pena prevista. Essa relativização das penas é coerente com uma análise que não privilegia a resposta como comportamento, mas leva em conta todo o contexto antecedente e consequente das respostas emitidas. Além disso, considera o entrelaçamento de várias contingências comportamentais com seus produtos e consequências culturais, ou seja, contingências e metacontingências. Assim, é possível tornar as consequências compatíveis com a gravidade das 
consequências da ação e com a situação. Um exemplo marcante disso é o paragrafo quinto do Art. 121.

$\S 5^{\circ}$ - Na hipótese de homicídio culposo, o juiz poderá deixar de aplicar a pena, se as consequências da infração atingirem o próprio agente de forma tão grave que a sanção penal se torne desnecessária.

Nesse paragrafo, a lei privilegia a consequência natural e idiossincrática do comportamento em detrimento de uma consequência arbitrária imposta pela cultura. Pressupõe-se que se "a consequência da infração atingir o próprio agente de forma grave" torna-se desnecessária uma sanção legal, pois essa consequência já produziria a diminuição da possibilidade do agente continuar emitindo o comportamento criminoso. Assim, um pai que por acidente atropela seu filho, levando-o a óbito, não deve ser responsabilizado penalmente por isso, afinal, a perda já seria suficientemente punitiva para seu comportamento de dirigir com displicência. Por outro lado, o parágrafo deixa a decisão para o juiz que é responsável por decidir se tal consequência é grave suficiente para que a pena não seja aplicada, sem nenhum critério objetivo para tal decisão, ou seja, sem a descrição de em que ambiente esse comportamento de "deixar de aplicar a pena" seria reforçado. Menos ainda quais as consequências possíveis para essa resposta.

\section{Comportamento Social e Contingências Comportamentais Entrelaçadas}

Enquanto descrição de práticas culturais é importante notar que muitos artigos do Código Penal estão relacionados a comportamentos de cidadãos e de agentes da lei. Por exemplo, a aplicação da pena (resposta do juiz) prevista para um comportamento considerado criminoso tem como estímulo antecedente o próprio comportamento criminoso (resposta do cidadão) e estabelece qual será a consequência para o mesmo. Assim, pode-se enquadrar essas descrições na definição de comportamento social (Skinner, 1953; Sampaio \& Andery, 2010). O cumprimento da contingência comportamental de um depende da emissão da resposta de outro indivíduo. A aplicação da pena por um juiz depende da emissão do comportamento criminoso e essa pena é a consequência desse comportamento.

A Parte Especial do Código Penal, citada anteriormente, oferece diversos exemplos desse tipo de descrição de comportamentos de indivíduos que servem de ambiente para o comportamento de outro(s). Nessa parte, são listados os que são considerados crimes e são especificadas as penas previstas para cada um deles. Por exemplo:

Art. 132. Expor a vida ou a saúde de outrem a perigo direto e iminente:

Pena - Detenção, de 3 (três) meses a 1 (um) ano, se o fato não constituir crime mais grave.

Outro exemplo:

Art. 151. Devassar indevidamente o conteúdo de correspondência fechada, dirigida a outrem;

Pena- detenção, de 1(um) a 6 (seis) meses, ou multa.
Muitos exemplos podem ser encontrados e todos mostram essa característica, em que uma prescrição de uma pena (comportamento do juiz) é consequência para um crime cometido (comportamento do criminoso) e tem o comportamento criminoso como estímulo discriminativo. É importante notar também que o cumprimento completo das contingências descritas requer que sejam emitidos comportamentos de mais de uma pessoa. Todas essas contingências comportamentais se entrelaçam de forma complexa e esses entrelaçamentos podem ou não estar descritos no próprio código. Assim, os dois exemplos acima possibilitam notar que não basta um juiz e um criminoso para que a pena seja aplicada. É necessário que policiais, agentes penitenciários e vítimas se comportem de maneira entrelaçada. Ou seja, para que o juiz possa minimamente ter acesso ao crime, é preciso que esse entrelaçamento aconteça.

Apesar de ser menos comum, existem algumas descrições de contingências comportamentais entrelaçadas no Código Penal que produzem consequências diferentes em longo prazo. Para exemplificar pode-se usar o inciso VIII do Art. 107 no qual é possível observar que a extinção da punibilidade (determinada pelo juiz) é consequência de um entrelaçamento que evolve além de comportamentos do próprio juiz, pelo menos, os do agente e da vítima.

\section{Art. 107. Extingue-se a punibilidade:}

VIII - pelo casamento do agente com a vítima, nos crimes contra o costume, definidos nos Capítulos I, II e III do Título VI da Parte Especial deste Código.

Para um planejamento cultural efetivo é necessário atentar para essas situações, afinal é importante que se esteja disposto a analisar os antecedentes, as respostas e as consequências de um comportamento que se pretende instalar, no caso, de uma prática cultural que se espera que seja aderida por um grupo. Assim, se o antecedente ou a consequência de um comportamento esperado for o comportamento de outro, a análise se estende a esse comportamento do outro.

\section{CONSIDERAÇÕES FINAIS}

O Código Penal é uma lei, como tal, é produto de comportamento verbal e não tem nenhum poder a priori sobre o comportamento dos cidadãos. Como conjunto de regras, o código deve ser efetivo em produzir mudanças no comportamento de seus "ouvintes" (no caso, todos que estão a ele submetidos) e sua formulação deveria seguir determinados parâmetros para aumentar sua efetividade. Uma regra, mesmo que emitida com status legal, não tem qualquer característica especial que lhe garanta controle e não é seguida pelo simples fato de descrever a contingência. É necessária uma história prévia de consequências reforçadoras diante do comportamento de "seguir regras" e mais, de seguir o tipo de regra em questão, no caso, uma lei.

Outro fator importante para aumentar o seguimento das regras, segundo Paracampo e Albuquerque (2005) é a correspondência entre a descrição e a 
"realidade" da contingência descrita. Ou seja, quando os comportamentos descritos nas regras são seguidos de forma sistemática pelas consequências previstas pela mesma regra, o seguimento dela se torna mais provável. Sobre o controle de regras no que se refere a aspectos culturais, Baum (1995) argumenta que uma regra pode ser seguida em função de consequências imediatas que podem não ter relação direta com a especificada pela própria regra. O quanto o comportamento governado pelas regras é monitorado é também fator importante, destacado por Paracampo e Albuquerque (2005), para o efetivo controle das regras.

Por um lado, seria produtivo que ao criar ou modificar o Código Penal o legislador tivesse ciência dessas variáveis que potencializariam o poder de controle desta lei. Por outro, é importante destacar que não é responsabilidade do legislador, nem objetivo do Código Penal, garantir que as consequências previstas por ele sejam de fato aplicadas, nem promover consequências imediatas intermediárias que sejam apresentadas para as respostas especificadas, até que a consequência prevista seja aplicada. Ainda, é obrigação de outros agentes promover a fiscalização do cumprimento da norma. Portanto, é importante destacar o Código Penal como elemento de um entrelaçamento muito maior que envolve ações de muitas pessoas e de organizações para que tenha a produção agregada imediata e gere a consequência cultural esperada.

A prioridade de controle aversivo em todo o Código Penal apresenta um problema adicional, além do já mencionado problema ético desse tipo de controle (Catania, 1999; Sidman, 1989/2001): por descrever consequências aversivas para comportamentos que se pretende evitar, o Código Penal pode não ser efetivo em evitar tais comportamentos. Considerando que as consequências só podem acontecer após a resposta punível (e se ela tiver o efeito prejudicial), tais consequências só vão aparecer depois que o dano já foi causado. A não ser que o objetivo do Código Penal seja meramente punitivo e vingativo (nos moldes do Código de Hamurabi), sem nenhuma função de controle prévio do comportamento, são necessárias adequações no planejamento cultural para impedir a ocorrência das respostas especificadas no código.

Uma discussão que não aparece na presente análise, mas que é constantemente apresentada por alguns setores da sociedade (inclusive por alguns legisladores) como solução em termos de prevenção de crimes, é o endurecimento das penas. Isso parece demonstrar uma crença de que a previsão (ou ameaça) de consequências cada vez mais aversivas diminuiria a probabilidade de engajamento dos cidadãos nas respostas especificadas pelo Código. De acordo com esse argumento, a previsão de pena de morte, o aumento do tempo de encarceramento ou mesmo a diminuição da maioridade penal (que colocaria os menores sob a égide do Código Penal) seriam eficazes na prevenção da violência.

A proposição de que o endurecimento das penas previne crimes só poderia ser uma solução no sentido de prevenção se as questões relacionadas à efetividade do controle das regras, apresentadas acima, fossem levadas em consideração e os problemas relacionados a elas fossem solucionáveis apenas por reformulações do texto do Código Penal. Endurecer as penas também poderia ser efetivo na diminuição do comportamento criminoso se as pessoas pudessem aprender com o exemplo daqueles que sofreram a punição. Porém, a imitação pode não ser suficiente, tendo em vista a complexidade de fatores envolvidos na aprendizagem, a partir da interação do indivíduo com o seu mundo. Portanto, não há uma relação direta entre observar uma determinada sanção sendo aplicada a um comportamento criminoso e a diminuição da emissão desse comportamento pelo observador. O observador estará envolvido em contingências individuais ou sociais (e.g., metacontingências) que selecionarão inúmeras ações em seu repertório comportamental, durante toda sua história de vida.

A análise apresentada no presente estudo mostra que algumas pequenas mudanças estruturais na forma como é escrito o Código Penal podem ser adequadas para melhorar o seu controle. Se as descrições completas fossem apresentadas juntamente com essas regras, elas poderiam cumprir um efeito discriminativo mais poderoso sobre os comportamentos das pessoas cujo comportamento é controlado pelo Código Penal. Também a especificação das consequências para os comportamentos das autoridades seriam recomendáveis tanto para produzir mais adesão desses, como para possibilitar um contra controle mais efetivo. Porém, considerando que algumas variáveis, para que as regras e as leis exerçam efetivamente controle, não podem ser manipuladas pela simples modificação textual do código; melhorias na estrutura do texto ainda não seriam suficientes para produzir a segurança social pretendida.

Novamente se destaca o fato de que o Código Penal é apenas um elo em um entrelaçamento comportamental complexo, que depende do comportamento de muitos agentes. Toda uma modificação nas contingências sociais daqueles que estão sujeitos a essa lei precisa ser realizada. Agências educacionais precisam ser acionadas e equipadas tanto para fazer com que as leis sejam conhecidas, quanto que os cidadãos aprendam efetivamente a seguir regras, e tenham em seus repertórios comportamentos alternativos bem instalados. Também outros setores da agência governamental precisam ser efetivos em produzir condições para que comportamentos alternativos possam ocorrer e ser reforçados.

Assim, a presente análise do Código Penal, feita a partir dos princípios da Análise do Comportamento, conclui que o documento poderia ser mais bem planejado para cumprir seu objetivo na cultura: que é controlar o comportamento dos membros dessa comunidade no sentido de diminuir comportamentos prejudiciais aos outros membros e para as agências governamentais. Ressalta-se que o bem dos membros da cultura e os bens da agência podem ser antagônicos e que a agência tende a agir em prol da manutenção do seu poder, segundo a análise skinneriana (e.g., Skinner, 1986). Por isso, apesar de esse assunto não ser alvo da regulamentação do Código 
Penal, vale a prescrição de que os membros da agência estejam expostos às mesmas contingências dos outros membros da cultura, pois isso garantiria que o controle da agência fosse direcionado ao bem comum. Em relação ao Código Penal, essa prescrição parece ser parcialmente atendida, pois os membros da agência governamental estão sujeitos às sanções previstas por eles, apesar de terem fórum privilegiado.

Conclui-se que a estrutura do Código Penal não é a mais indicada para o controle efetivo dos comportamentos. A disposição dos artigos que descrevem os termos da contingência comportamental nem sempre é a mais adequada, por terem a descrição de comportamentos criminosos e de suas consequências de forma dispersa no documento. Há, no entanto, consequências previstas para os comportamentos que se pretende evitar, descritas adequadamente logo após a descrição desses comportamentos. Também é problemática em relação à efetividade do controle, a falta de consequências prescritas para alguns comportamentos, principalmente, os comportamentos dos agentes da lei, o que gera um problema ético adicional: a diminuição da possibilidade de contra controle. Considerando, como Páramo (2013), que apesar de não ter que ser exclusivo, o controle por regras é importante para o cumprimento de normas sociais e legais, que algumas formulações de regras são mais efetivas que outras e diante da constatação de que há falha na formulação das regras regulamentadas no Código Penal, torna-se necessário um planejamento da reformulação e adequação dessa lei.

A análise do Código Penal brasileiro como parte de uma metacontingência, que deveria produzir como consequência cultural a segurança dos cidadãos, mostra que além dos problemas estruturais para o controle do comportamento, tal metacontingência é insuficiente para cumprir seu objetivo. Apesar de insuficiente, o Código Penal, não é prescindível em um contexto de ações que objetivam uma sociedade segura. É possível entender o Código Penal como uma parte de uma metacontingência maior que envolve outras leis e outras práticas (aquelas que tradicionalmente são delegadas ao controle da agência governamental), e assim observar que como parte desse entrelaçamento ele é importante, apesar da necessidade de revisão.

\section{REFERÊNCIAS}

Abreu, P. R., \& Hübner, M. M. C. (2011). Efeito de instruções sobre respostas de checagem. Psicologia Teoria e Pesquisa, 27, 301-308. doi:10.1590/S010237722011000300005

Albuquerque, L. C., \& Paracampo, C. C. P. (2010). Análise do controle por regras. Psicologia USP, 21, 253-273. http://dx.doi.org/10.1590/S010365642010000200004

Albuquerque, L. C., Paracampo, C. C. P., Matsuo, G. L., \& Mescouto, W. A. (2013). Variáveis combinadas, comportamento governado por regras e comportamento modelado por contingências. Acta Comportamentalia, 21, 285-304.
Barros, R. S. (2003). Uma introdução ao comportamento verbal. Revista Brasileira de Terapia Comportamental e Cognitiva, 5, 73-82.

Baum, W.M. (1995). Rules, culture and fitness. The Behavior Analyst, 18, 1-21.

Baum, W.M. (2005). Understanding behaviorism: Behavior, culture and evolution. Malden: Blackwell Publishing. (Obra original publicada em 1994).

BRASIL (2012). Código Penal Brasileiro, Brasília, Brasil.

Cabral, M. D. C. (2014). Contingências e metacontingências envolvidas no processo legislativo da Lei 12.433, de 29 de Junho de 2011. (Dissertação de Mestrado) Universidade de Brasília. Brasília. Recuperado de http://repositorio.unb.br/bitstream/10482/18607/1/2014 _MarizaDomicianoCarneiroCabral.pdf

Catania, A. C. (1999). Aprendizagem: Comportamento, linguagem e cognição (D. G. Souza Trad.). Porto Alegre: Artmed. (Obra original publicada em 1998).

Carvalho, I. C. V. (2013). Contingências $e$ metacontingências na Lei de Diretrizes e Bases da Educação - LDB. (Dissertação de Mestrado) Universidade Brasília. Brasília, Distrito Federal. Recuperado de http://repositorio.unb.br/bitstream/10482/15442/1/2013 _IzabelCristinaValedeCarvalho.pdf

Castro, M. S. L. B. (2013). O naturalismo ético no Behaviorismo Radical de B. F. Skinner. (Tese de doutorado) Universidade Federal de São Carlos. São Carlos. Recuperado de http://www.dfmc.ufscar.br/uploads/publications/525bf 6b53e01e.pdf

Dittrich, A., Melo, C. M., Moreira, M. B., \& Martône, R. C. (2013). O modelo de seleção pelas consequências: O nível cultural. In M. B. Moreira (Org.), Comportamento e práticas culturais. (pp. 45-55). Brasília: Instituto Walden4.

Glenn, S., \& Mallot, M. E. (2004). Complexity and selection: Implication for organizational change. Behavior and Social Inssues. 13, 89-106. http://dx.doi.org/10.5210/bsi.v13i2.378

Lourencetti, L. A. (2015). Descrição e análise de contingências presentes em legislações referentes à mobilidade urbana.(Dissertação de Mestrado). Universidade Estadual Paulista Júlio Mesquita Filho, Bauru.

http://repositorio.unesp.br/bitstream/handle/11449/132 491/000852951.pdf?sequence=1\&isAllowed=y

Machado, V. L. S. (2007). O comportamento do brasiliense na faixa de pedestre: um exemplo de uma intervenção cultural. (Dissertação de mestrado). Universidade de Brasília, Brasília, Brasil. Recuperado de http://repositorio.unb.br/bitstream/10482/3512/1/Disse rt_Vivica.pdf

Mallot, M. E., \& Glenn, S. (2006). Targets of intervention in cultural and behavioral changes. Behavior and Social Issues, $\quad 15, \quad 31-56$. http://dx.doi.org/10.5210/bsi.v15i1.344 
Martins, A. L. A. (2009). O Sistema Único de Saúde: contingências e metacontingências nas Leis Orgânicas de Saúde. (Dissertação de Mestrado). Universidade de Brasília. Brasília, Brasil. Recuperado de http://repositorio.unb.br/bitstream/10482/7749/1/2009_ AndreLuizAlmeidaMartins.pdf

Moreira, M. B., Machado, V. L. S., \& Todorov, J. C. (2013). Cultura e práticas culturais. In M. B. Moreira (Org.), Comportamento e práticas culturais. (pp. 1423). Brasília: Instituto Walden 4.

Paracampo, C. C. P., \& Albuquerque, L. C. (2005). Comportamento governado por regras: revisão crítica de proposições conceituais e resultados experimentais. Interação em Psicologia, 9, 227-237. doi: 10.5380/psi.v9i2.4798

Páramo, P. (2013). Comportamiento urbano responsable: Las reglas de convivencia em el espacio público. Revista Latino Americana de Psicologia, 45, 475-487. doi: 10.14349/rlp.v45i3.1488

Sampaio, A. A. S., \& Andery, M. A. P. A. (2010) Comportamento social, produção agregada e prática cultural: uma análise comportamental de fenômenos sociais. Psicologia: Teoria e Pesquisa, 26, 183-192. doi: 10.1590/S0102-37722010000100020

Sidman, M. (2001). Coercion and its fallouts. Boston: Authors Cooperative. (Originalmente publicado em 1989).

Skinner, B. F. (1953). Science and human behavior. New York: Macmillan.

Skinner, B. F. (1957). Verbal behavior. New York: Apleton-Century-Crofts, Inc.

Skinner, B. F. (1973). Beyond freedom and dignity. Meddlesex: Pelican Books. (Originalmente publicado em 1971).

Skinner, B. F. (1974). About behaviorism. New York: Alfred A. Knopf.

Skinner, B. F. (1981). Selection by consequences. Science, 213, 501-504. doi: 10.1126/science.7244649

Skinner, B. F. (1986). What is wrong with daily life in western world? American Psychologist, 45, 568-574. http://psycnet.apa.org/doi/10.1037/0003066X.41.5.568

Todorov, J. C. (1987). Constituição como metacontigência. Psicologia, Ciência e Profissão, 1, 913. doi: 10.1590/S1414-98931987000100003

Todorov, J. C. (2005). Laws and complex control of behavior. Behavior and Social Issues. 15, 92- 94. http://dx.doi.org/10.5210/bsi.v14i2.360

Todorov, J. C. (2009). Behavioral analysis of nonexperimental data associated with cultural practices. Behavior and Social Issues, 18, 10-14. http://dx.doi.org/10.5210/bsi.v18i1.2756

Todorov, J. C., Moreira, M., Prudêncio, M. R. A., \& Pereira, G. C. C. (2004). O Estatuto da Criança e do Adolescente como metacontingência: um estudo de contingências e metacontingências no Estatuto da Criança e do Adolescente. In M. Z. S., Brandão; F. C. S., Conte; F. S, Brandão, Y. K., Ingberman; V. M., Silva, S. M., Oliane (Orgs.), Sobre comportamento e cognição: contingências e metacontingências contextos sócio verbais e o comportamento do terapeuta. (v.13, pp.44-51). Santo André, SP. ESETEC. 